\title{
POETRY
}

\section{"Shirt, brown, honesty"}

As I steer him through another corridor he murmurs, "Is this part of the test? Because this place looks like a bloody maze." "What were the three words I asked you to remember?" I ask the woman I am assessing. Encircled by folds of defiant skin, her eyes, sapphires under the fluorescent light, sparkle. She exclaims, "'Integrity', right?" Unasked, he recalls, the words. She forgets, her name. He sings passionately, letters and sounds punctuated by grunts: poetry, in an exotic language. "Shirt, brown, honesty," she answers. "You know how I remembered? You have a brown skin, you're wearing a shirt, and you seem like an honest young fella." Chatters and hush. The waiting room is reliving blaring angst, and moments of unspoken resolve. Faces converge, names escape me now too. Shirt. Brown. Honesty. For the tenth time this hour, the young man says, "I am your son, mom." His eyes crawl over my fingers, resting on my silver watch. A daughter says, "You have such a warm calming voice."

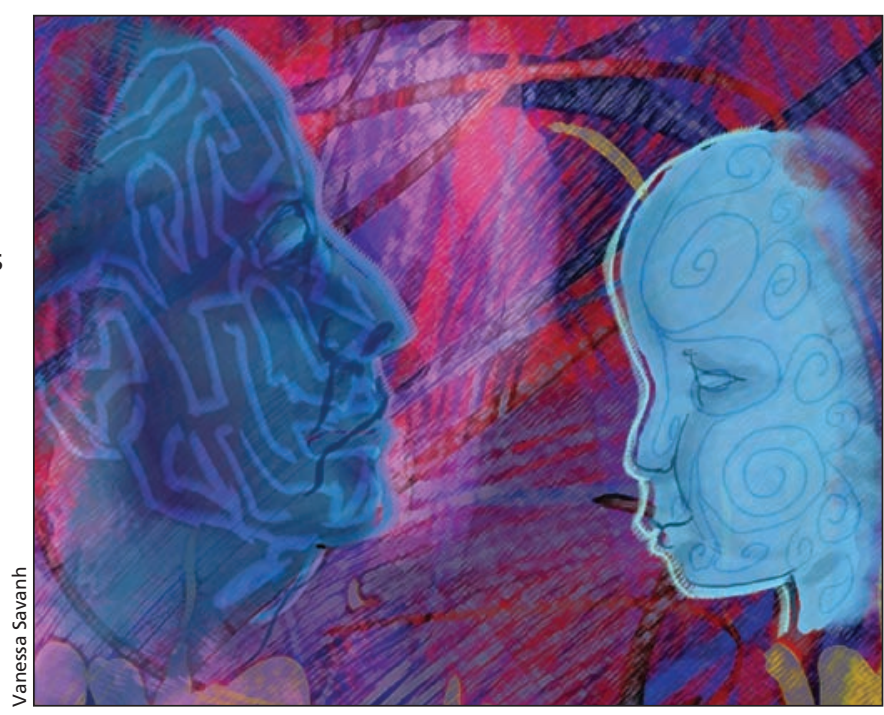
I interrogate her mother, as a scientist should, trying to find a way out of this maze. Her eyes gaze at mine. She is trying to find her way through the labyrinth of professionalism, to a place where we both stand as fragile human beings. Shirt. Brown. Honesty. It could be me on the other side of the brown table. In fact I already am. I reach out — I must hold on.

\section{Arash Emamzadeh BA}

Poet

Burnaby, BC

The author keeps an experimental poetry blog: http://seafloors.blogspot.com 